\title{
Open Versus Closed Treatment of Mandibular Condyle Fracture
}

\section{Reda Elgazzar*}

Faculty of Dentistry, Division of Oral and Maxillofacial Surgery, Dental Diagnostics and Surgical Sciences, University of Manitoba, Canada

I believe that, removing barriers to research published online will greatly enrich the scientific literature and enhance dissemination of the information. Dentistry Journal (part of OMICS group) is an Open Access Dental Journal which is aimed at publishing the most exciting researches with respect to the subjects of dentistry, providing a rapid turn-around time possible for reviewing and publishing, and disseminating the articles freely for research, teaching and reference purposes. This month editorial is about an important debatable issue among the Oral and Maxillofacial Surgeons worldwide, Management of Mandibular condylar fracture.

Mandibular condyle fracture is an extremely common injury in facial trauma, accounting for approximately $29-40 \%$ of facial bone fractures [1], and $20-52 \%$ of all mandibular fractures [2,3]. Despite its regularity, it has been a contentious topic in maxillofacial trauma for some time with regards to its diagnosis, classification, and management.

The focus of the controversy, centers on the choice of management. Two main treatment modalities have been used to manage condylar fractures: open and closed treatment. For years, closed treatment using Maxilla Mandibular Fixation (MMF) was the preferred method of treatment and was thought to be essentially complication free $[4,5]$. However, serious complications have been reported including Temporomandibular Joint (TMJ) ankylosis, malocclusion, mandibular deviation, and pathological changes to the condylar process [6]. With improvements in imaging, osteosynthesis materials, and surgical techniques, Open Reduction/Internal Fixation (ORIF) has become a more common treatment option. ORIF is a technically difficult operation and complications such as facial palsy, secondary infection, fistula formation, and postoperative scarring have also been reported
$[7,8]$. However, it has the advantage of being less disruptive to a patient's quality of life post-treatment. A third option, non-invasive conservative treatment, is also indicated in some patients, particularly those with no displacement of the condyle or occlusal disturbances [9].

To date, no general consensus has been reached in the literature favoring any specific treatment modality. Fractures of the mandibular condyle deserve special consideration amongst mandibular fractures because of the condyle's functional role as a moving unit and the potential for serious complications following treatment [9].

\section{References}

1. Olson RA, Fonseca RJ, Zeitler DL, Osbon DB (1982) Fractures of the mandible: a review of 580 cases. J Oral Maxillofac Surg 40: 23-28.

2. Larsen OD, Nielsen A (1976) Mandibular fractures. I. an analysis of their etiology and location in 286 patients. Scand J Plast Reconstr Surg 10: 213-218.

3. Ellis E 3rd, Moos KF, el-Attar A (1985) Ten years of mandibular fractures: an analysis of 2137 cases. Oral Surg Oral Med Oral Pathol 59: 120-129.

4. Cook RM, MacFarlane WI (1969) Subcondylar fracture of the mandible. a clinical and radiographic review. Oral Surg Oral Med Oral Pathol 27: 297-304.

5. MacLennan WD (1952) Consideration of 180 cases of typical fractures of the mandibular condylar process. Br J Plast Surg 5: 122-128.

6. Ellis E 3rd (1998) Complications of mandibular condyle fractures. Int J Ora Maxillofac Surg 27: 255-257.

7. Ellis E 3rd, Throckmorton G (2000) Facial symmetry after closed and open treatment of fractures of the mandibular condylar process. J Oral Maxillofac Surg 58: 719-728.

8. Lima SM Jr, Asprino L, Moreira RW, de Moraes M (2011) Surgical complications of mandibular condylar fractures. J Craniofac Surg 22: 1512-1515.

9. Montazem AH, Anastassov G (2009) Management of condylar fractures. Atlas Oral Maxillofac Surg Clin North Am 17: 55-69.
*Corresponding author: Reda Elgazzar BDS, MSc, PhD, Faculty of Dentistry, Division of Oral and Maxillofacial Surgery, Dental Diagnostics and Surgical Sciences, University of Manitoba, Canada, Tel: 204-789-3634; E-mail: elgazzar@cc.umanitoba.ca

Received December 05, 2012; Accepted December 05, 2012; Published December 07, 2012

Citation: Elgazzar R (2012) Open Versus Closed Treatment of Mandibular Condyle Fracture. Dentistry 2: e110. doi:10.4172/2161-1122.1000e110

Copyright: (C) 2012 Elgazzar R. This is an open-access article distributed unde the terms of the Creative Commons Attribution License, which permits unrestricted use, distribution, and reproduction in any medium, provided the original author and source are credited. 